\title{
Cellulase Activity in Solid State Fermentation of Palm Kernel Cake with Trichoderma sp.
}

\author{
Tengku Norsalwani Tuan Lah ${ }^{1}$, Nik Norulaini Nik Ab. Rahman ${ }^{1 *}$, Nurul Jannah Hasnan ${ }^{1}$, Moftah Massaud Ben \\ Name $^{1}$, Hideyuki Nagao ${ }^{2}$, Mohd Omar Ab Kadir ${ }^{3}$
}

\author{
${ }^{1}$ School of Distance Education, Universiti Sains Malaysia (USM), 11800 Minden, Penang, Malaysia. \\ ${ }^{2}$ School of Biological Sciences, Universiti Sains Malaysia (USM), 11800 Minden, Penang, Malaysia \\ ${ }^{3}$ School of Industrial Technology, Universiti Sains Malaysia (USM), 11800 Minden, Penang, Malaysia \\ E.mail: norulain@usm.my
}

Received $18^{\text {th }}$ January 2012; Received in revised form $2^{\text {nd }}$ May 2012; Accepted $4^{\text {th }}$ May 2012

\begin{abstract}
Aims: The effect of different types of fungal inocula to the cellulase activity measured on palm kernel cake (PKC) was studied.

Methodology and Results: Isolate Pro-A1 which was identified as Trichoderma sp. was selected as a potential producer of cellulase via solid state fermentation technique (SSF). Two types of PKCs were used; raw PKC (containing residual oil) and defatted PKC. The PKCs were inoculated with different concentrations of conidia and varying amounts (g) of solid mycelia plugs (SMP) for SSF. The effect of ultrafiltered crude fungal filtrate (CFF) as inocula was also being tested. The highest cellulase activity of $2.454 \mathrm{FPU} / \mathrm{ml}$ was detected with $60 \%$ (wt/wt) SMP applied to the raw PKC. Conversely, $2.059 \mathrm{FPU} / \mathrm{mL}$ of cellulase activity was measured when $80 \%$ (wt/wt) of SMP was applied to the defatted PKC which is $62.3 \%$ higher than the untreated defatted PKC; and more than $100 \%$ increase in enzymatic activity compared to raw PKC. The cellulase activity in the SSF inoculated with $8 \times 10^{6}$ conidia $/ \mathrm{mL}$ and $12 \times 10^{6} \mathrm{conidia} / \mathrm{mL}$ were $1.704 \mathrm{FPU} / \mathrm{mL}$ for raw PKC and $1.856 \mathrm{FPU} / \mathrm{mL}$ for defatted PKC, an enhancement of about $46 \%$ from uninoculated batch. Inoculation with CFF bears corresponding maximum improvement of the cellulase activity on both PKCs of $13.58 \%$ (raw) and $2.86 \%$ (defatted).

Conclusion, significance and impact of study: The current study proves that Trichoderma sp. in the form of SMP can enhance the cellulase activity on PKCs effectively with more than $100 \%$ increment. Fungal conidia are also a better choice in enhancing cellulase activity of Trichoderma sp. permitted that the PKC used is devoid of oil. From this study, Trichoderma sp. holds the potential of converting lignocellulosic materials into products of commercial and industrial values such as glucose and other biofuels.
\end{abstract}

Keywords: Defatted Palm Kernel Cake, Raw Palm Kernel Cake; Cellulase activity, fungal conidia; fungal solid mycelial plug

\section{INTRODUCTION}

Every year, food, agriculture and forest industries are producing large volumes of waste worldwide; causing serious disposal problems especially in countries where the economy relies heavily on agriculture. The agricultural industry is under tremendous pressure to find an alternative use for its residual matter. These biological wastes are organic in nature and easily assimilated by the micro-organisms mainly fungi which make such wastes very appropriate for enzyme production under solid-state fermentation (SSF) conditions (Weiland, 1988). The use of these wastes considerably reduces the production costs. Therefore, solid state fermentation (SSF) is finding increasing application in the production of value added products from wastes mostly from lignocelluloses, agroindustrial and etc (Raghavao et al., 2003; Panagiotou et al, 2003; Pang et al, 2006a; Lee et al., 2011). The applications of SSF are not only at research levels on a laboratory scale (Gupte and Madamwar, 1997; Gutierrez-
Correa and Tangerdy, 1998; Hang and Woodams, 1998; Kotwal et al., 1998; Sekar and Balaraman, 1998), but also at pilot and industrial scales (Durand and Chereau, 1988; Xue et al., 1992; Durand et al., 1996; Fernandez et al., 1996). One of the biggest industries in Malaysia is the oil palm sector. Palm kernel cake (PKC) is one of the abundant by-products that are produced from the palm kernel extraction process. It was being produced at about 1.9 million tonnes yearly in 2003/2004 (Peter, 2005). The PKC constituents are mainly cellulose, hemi-cellulose and lignin used as bio-resource of raw materials for industries considering that it has been produced in large quantities (lluyemi et al., 2006).

Enzymes can be considered as hot items for industrial applications in Malaysia and has a huge commercial prospect (Pang et al., 2006b). All the enzymes used in Malaysia are mainly imported from Denmark, Netherlands, Belgium and other countries. The import has been gradually increased to around USD 15.0 millions in year 
2003, which makes up $5 \%$ of the total market in Malaysia (Department of Statistics Malaysia., 2003). Due to the increase in demand for this enzyme, it has propelled the field of research on cellulases. Several studies are also being made on the use of cellulase in the bioconversion of agro industrial waste (Pricart et al., 2007). Using enzymes from filamentous fungi to recover cellulose from biomass is an example of green method for cellulose production. Cellulolytic enzymes from a filamentous fungus, Trichoderma sp. have been a subject of intensive research because this organism secretes large amounts of enzymes needed for complete hydrolysis of crystalline cellulose (Kubicek, 1992; Teeri et al., 1992).

The present study focused on the cellulase activity of raw and defatted palm kernel cake solid state fermentation inoculated with solid mycelia plug and conidia of Trichoderma sp. The objective of the research is to determine the cellulase activity on PKC with and without residual oil, as a function of inocula type, vis mycelia plug, conidia and crude extract.

\section{MATERIALS AND METHODS}

Isolation and Identification of Isolate Pro-A1, the Potential Producer of Cellulase

The isolation of fungi was done by dipping a sterilized oil palm wood chip into the commercially available agricultural bio-fertilizer from Malaysian company, Pro-Fil Sdn. Bhd. The wood chip was then cultured on nutrient agar for 7 days at $25^{\circ} \mathrm{C}$ and $9 \mathrm{~h}$ white light under sterilized conditions. The uncontaminated wood chips were taken based on control (sterilized wood chip only). The fungal that grew on the wood chip surface was identified as Trichoderma sp. by using the light microscope. Uncontaminated wood chips based on control were removed and transferred to $30 \%$ mixed vegetable agar media, and after a week, the culture grew completely over the media. A piece $\left(2 \mathrm{~mm}^{2}\right)$ of the culture is then subcultured onto a fresh media and identified. The fungal identification was carried out based on the colony morphologies and structural characteristics as observed under the light and scanning electron microscopy.

\section{Sampling and Preparation of Palm Kernel Cake}

Freshly produced palm kernel cake was obtained from a local palm kernel mill namely Fleet Palms Sdn. Bhd. Located at Sungai Jawi, Penang. The fresh samples had undergone the screw press method in extracting the oil and divided into two portions. A portion was immediately stored at $4{ }^{\circ} \mathrm{C}$ in a refrigerator until later use and labeled as raw PKC. Another portion was defatted using Soxhlet technique with hexane as solvent and extraction carried out for $8 \mathrm{~h}$. The residual hexane was then removed and the defatted PKC was stored at $4{ }^{\circ} \mathrm{C}$ until ready for use. Proximate analysis was carried out for all the substrates based on the methods described by AOAC (1997).

\section{Fungal Cultivation and Inocula Preparation}

The mixed vegetable broth for fungal cultivation was prepared by mixing $163 \mathrm{~mL}$ of mixed vegetable juice (V8 commercial brand) and $380 \mathrm{~mL}$ of sterile distilled. The $\mathrm{pH}$ of the medium was adjusted to $\mathrm{pH} 5.0$ and autoclaved at $1.03 \times 10^{5} \mathrm{~Pa}, 121^{\circ} \mathrm{C}$ for $15 \mathrm{~min}$. About $1.0 \mathrm{~g}$ of Trichoderma sp. mycelia plug was inoculated onto the V8 solid medium, incubated at $30^{\circ} \mathrm{C}$ for 5 days. At the end of the fifth day, a piece of the colony with size circa $2 \mathrm{~mm}^{3}$ was cut from the periphery of the culture where the growth is most active and inoculated into sterile liquid V8 media. The inoculated liquid medium was further incubated for 5 days at $30{ }^{\circ} \mathrm{C}$ on a rotary shaker at $150 \mathrm{rev} / \mathrm{min}$. The liquid medium was then filtered and both the biomass and the filtrates collected (containing conidia to be used as inocula). The biomass was rinsed with the sterile distilled water to completely remove any trace of the medium. The conidia concentration was determined using a haemocytometer.

\section{Ultrafiltration of fungal culture to remove the conidia}

The filtrates from the fungal culture, was further filtered by using the ultrafiltration $0.45 \mu \mathrm{m}$ of nylon filter in order to remove the conidia to obtain the crude fungal filtrate and used as an inocula for the SSF.

\section{Solid State Fermentation}

Solid state fermentation of fungus was performed with $5 \mathrm{gm}$ ground PKC as the solid substrate. The substrate was autoclaved at $1.03 \times 10^{-5} \mathrm{~Pa}, 121^{\circ} \mathrm{C}$ for $15 \mathrm{~min}$ and cooled to room temperature before inoculated with different concentrations of fungi conidia: $4 \times 10^{6}, 8 \times 10^{6}$, $12 \times 10^{6}, 16 \times 10^{6}$ and $20 \times 10^{6}$ conidia/mL. Another set of substrates were inoculated with different volume of crude extract to $5.0 \mathrm{~g} \mathrm{PKC} \%$ (vol/wt): $10 \%, 20 \%, 40 \%, 60 \%$, $80 \%$ and $100 \%$. Different weight ratios of the solid mycelia plug (SMP) to $5.0 \mathrm{~g}$ PKC (wt/wt): $10 \%, 20 \%, 40$ $\%, 60 \%, 80 \%$ and $100 \%$ were prepared. The PKC and the SMP are mixed thoroughly and allowed to ferment for five days. Sterile distilled water was added just enough to keep the PKC moist. The initial pH was 5.2 and the entire samples and controls without inoculation were incubated for five days at ambient temperature.

\section{Enzyme Extraction}

At the end of the fifth day of fermentation, as much as 20 $\mathrm{mL}$ of sterile distilled water was added to the SSF substrate PKC and swirled until it homogeneous. All the flasks were vigorously shaken on the rotary shaker at 200 $\mathrm{rev} / \mathrm{min}$ for $30 \mathrm{~min}$. The solid biomass was separated from the suspension by filtration through Whatman filter paper no.1. The extract was used as the source of enzyme preparation. The procedure was repeated with different treated raw and defatted PKCs. 


\section{Measurement of Enzyme Activity}

Measurement of enzyme activity was carried out based on the method of filter paper assay for saccharifying cellulose (FPU Assay) outlined by (Ghose, 1987; Mandels et al., 1976). One $\mathrm{mL}$ of $0.05 \mathrm{M}$ citrate buffer ( $\mathrm{pH} 4.8)$ (prewarmed to $40.0 \pm 0.1{ }^{\circ} \mathrm{C}$ ) was added to the test tube containing 1 Whatman 1 filter paper strip $(1 \mathrm{~cm} \times 6 \mathrm{~cm})$. After that, $0.5 \mathrm{~mL}$ of sample solution (supernatant) also pre-warmed to $40.0 \pm 0.1{ }^{\circ} \mathrm{C}$ was added to the citrate buffer solution. The resulting solution was mixed thoroughly and then it was transferred to a water-bath maintained at $50.0 \pm 0.1^{\circ} \mathrm{C}$. After 60 min (reaction step) the test tubes were removed from the water bath, and 3 $\mathrm{mL}$ of 3,5-dinitrosalicylic acid (DNS) solution was added and mixed thoroughly to stop the enzymatic reaction. Tubes were covered and placed in a boiling water bath for $5 \mathrm{~min}$. All the tubes were cooled to room temperature with a cooling water bath. The absorbance was determined at $540 \mathrm{~nm}$ against water blank. Enzyme activity was expressed as FPU/mL (Amount of reducing sugar released per $\mathrm{mL}$ of filtrate per $\mathrm{h}$ ).

\section{Statistical Analysis}

The data in this experiment were analysed using Analysis of Variance (ANOVA) from Minitab 15 with $95 \%$ of confidence interval.

\section{RESULTS AND DISCUSSION}

Palm kernel cake consists of between $15 \%$ to $18 \%$ protein and $60 \%$ to $70 \%$ polysaccharides. The majority of the polysaccharides are non starch, comprising of betamannans type of hemicelluloses (Choi and Gandipon, 2006). The solid state fermentation of both raw PKC which still contains residual oil and defatted PKC, having the oil completely removed were tested with Trichoderma sp. in cellulase activity.

\section{Estimation of Cellulase Activity by Trichoderma sp. on Raw and Defatted PKC}

Addition of the solid mycelia plug (SMP) $60 \%$ by weight of the SSF exhibits enzyme activity of $2.454 \mathrm{FPU} / \mathrm{mL}$ yielding $5.67 \mathrm{mg}$ glucose per $\mathrm{mL}$ of extract. Figure 1 shows the growth of Trichoderma sp. fungal mycelia on the surface of raw PKC. This represents the highest cellulase activity of the range tested. Trichoderma sp. has been shown to produce cellulase in breaking down the cellulose present in palm kernel fiber (Pang et al., 2006b; Hong et al., 2011). The fungal presence resulted in higher enzyme activity, subsequently yielding more glucose. This is based on the action of cellulase produced by the fungus which can degrade the cellulose in the PKC to glucose. Saenphoom et al. (2011) reported a significant increase in the total reducing sugar after treatment of palm kernel expeller (PKE) using exogenous enzyme, suggesting the effective carbohydrates hydrolysis into monosaccharides sugar. Furthermore, Mackul'ak et al. (2010) proved that it is possible to decompose cellulose substrate to glucose by enzymes and figured out that the products of enzymatic degradation of substrates are glucose and lower aldehydes which are highly degraded in anaerobic processes.

Application of Trichoderma sp. SMP to the defatted PKC enhanced the cellulase activity by $62.3 \%$ compared to uninoculated substrate. With $60 \%$ (wt/wt) SMP, more than $100 \%$ increase of cellulase activity can be attained on raw PKC substrate. On the other hand, the highest cellulase activity measured on substrate inoculated with conidia, was about $1.856 \mathrm{FPU} / \mathrm{mL}$ which occurred when $12 \times 10^{6}$ conidia $/ \mathrm{mL}$ were used on defatted PKC, and 1.704 $\mathrm{FPU} / \mathrm{mL}$ cellulase activity on raw PKC inoculated with $8 \times 10^{6}$ conidia/mL. Approximately $46.4 \%$ and $46.5 \%$ higher cellulase activity were achieved with raw PKC and defatted PKC respectively. The growth of Trichoderma sp. conidia on PKC can be seen in Figure 2.

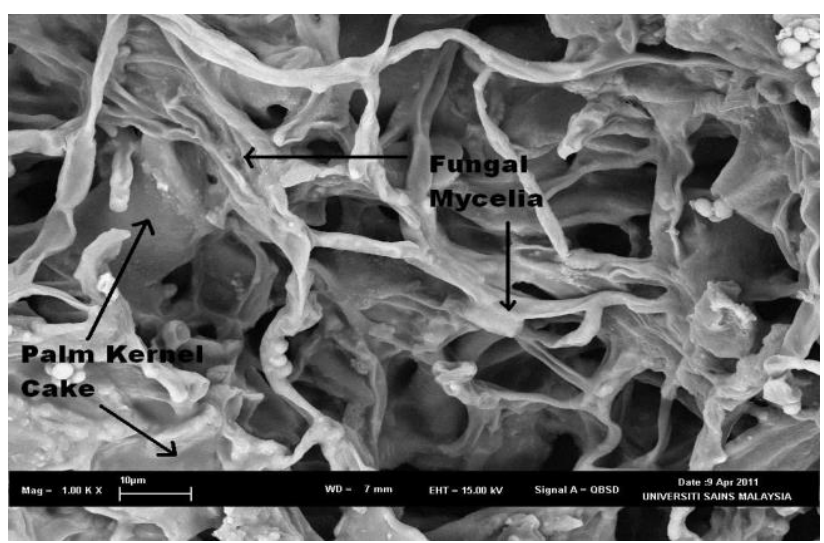

Figure 1: Five day old solid state fermentation showing Trichoderma fungal mycelia on the surface of raw palm kernel cake (1.0 K magnification)

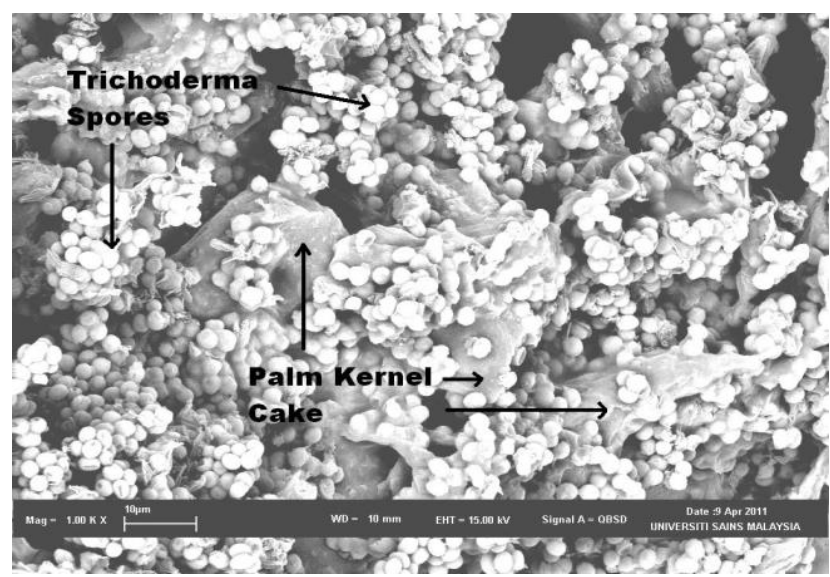

Figure 2: Five day old solid state fermentation showing Trichoderma spores on raw palm kernel cake (1.0K magnification) 
Difference in Enzyme Activities between Solid Mycelial Plug (SMP) and Conidia as Inocula

Solid mycelia plug (SMP) as inocula generated higher enzyme activity than conidia culture when tested on both raw and defatted PKC (Figures 3 and 4). The cellulase activity from the raw PKC inoculated with SMP was higher than from defatted PKC based on SMP/PKC ratio. The cellulase activity enhancement was about $49.6 \%$ for both raw and defatted PKC. The SMP/PKC ratio is crucial as long as the PKC as a substrate for Trichoderma sp. is not limiting to stimulate the production of cellulase. This means increasing cellulase activity will be observed until all the substrates, vis the PKCs are being broken down by the mounting mass of Trichoderma sp. present in the substrate. As the substrate is being reduced to simple sugars, the cellulase enzymatic process will be slowed down and eventually inhibited.

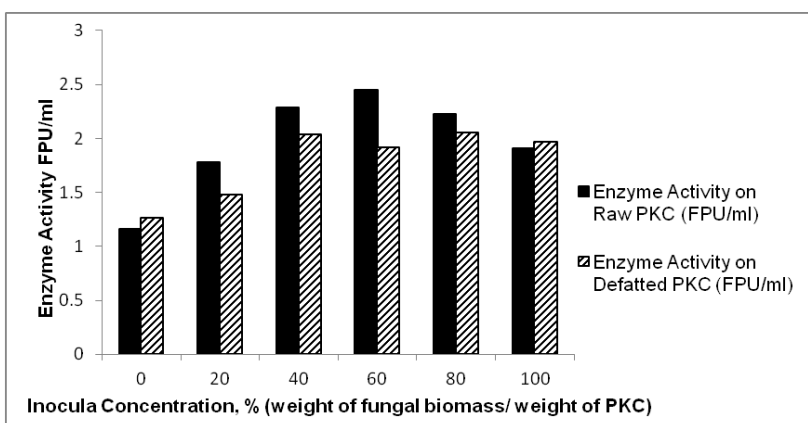

Figure 3: Cellulase activity of raw and defatted palm kernel cake solid state fermentation (PKC SSF) with different ratios of solid mycelia biomass to PKC

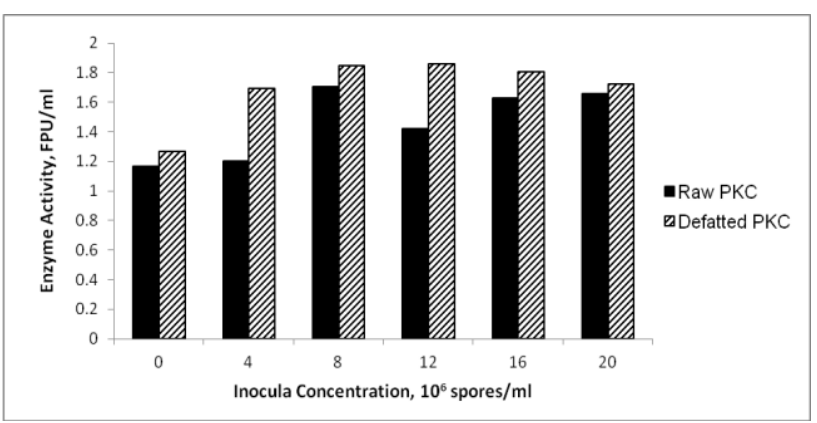

Figure 4: Cellulase activity of raw and defatted palm kernel cake solid state fermentation (PKC SSF) with different conidia concentrations

\section{Relationship between the production of glucose and cellulase activity by Trichoderma sp. on PKC}

Different enzymes have developed different ways of breaking down cellulose. Cellulolytic enzymes can be characterized as $C_{1}$ enzyme, $\beta-1,4$ glucanases (Exo- $\beta-1$, 4 glucanases and endo- $\beta-1,4$ glucanases) and cellobiases (King and Vessal, 1969). According to Figures $\mathbf{3}$ and $\mathbf{5}$, enzyme activity and glucose concentrations produced a linear relationship which means any increment in the enzyme activity will also increase the glucose concentration. The same results are observed in Figures 4 and 6.

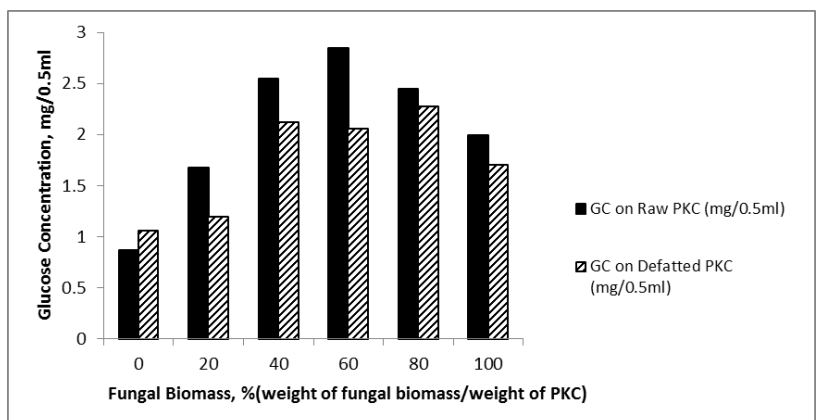

Figure 5: Glucose concentrations from raw and defatted palm kernel cake solid state fermentation (PKC SSF) with different ratios of solid mycelia biomass to PKC

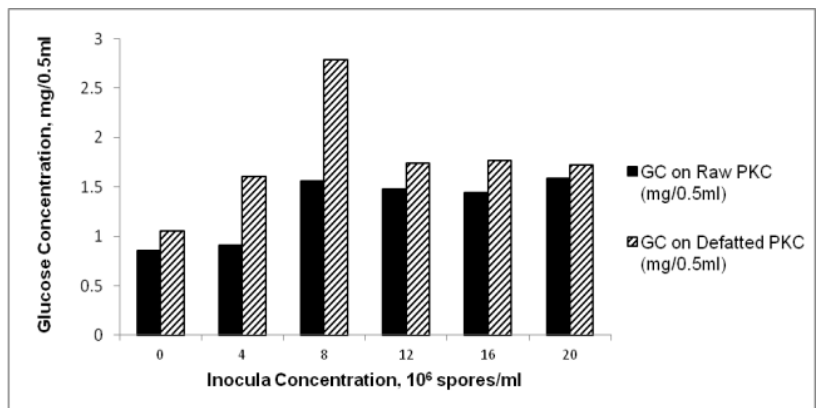

Figure 6: Glucose concentrations from raw and defatted palm kernel cake solid state fermentation (PKC SSF) with different conidia concentrations

\section{Effect of inocula}

Highest cellulase activity was detected from fermented defatted PKC with $12 \times 10^{6}$ conidia/mL as in Figure 4. Similar maximum increase of $46 \%$ in the cellulase activity was detected on both raw PKC and defatted PKC. The outcome from the use of crude fungal filtrate illustrated slower increase in cellulase activity. According to Figure 7 , the cellulase activity on the SSF using crude fungal filtrate show only $13.58 \%$ and $2.86 \%$ increase of the cellulase activity on raw and defatted PKC respectively. Figure 8 shows glucose production from inoculated defatted $\mathrm{PKC}$ is generally higher than raw $\mathrm{PKC}$, except when $100 \% \quad(\mathrm{v} / \mathrm{w})$ crude filtrate was used. At this concentration, the highest yield with $1.6 \mathrm{mg}$ glucose per $0.5 \mathrm{ml}$ media was determined on raw PKC, counter to the results obtained from lower inocula percentage. Based from the statistical analysis using analysis of variance (ANOVA) provided by Minitab 15, all treatments were significant with $p<0.005$ when tested with $95 \%$ confidence level. The two major factors that affect microbial yield of enzymes in a SSF system in this study are the substrate type and amount of inocula. 


\section{DISCUSSION}

\section{Estimation of Cellulase Activity by Trichoderma sp. on Raw and Defatted PKC}

The SSF of defatted PKC requires more than $60 \%$ (wt/wt) solid mycelial plug to produce enough enzymatic activity at $2.059 \mathrm{FPU} / \mathrm{mL}$ to breakdown cellulose, to yield as much as $4.544 \mathrm{mg}$ glucose $/ \mathrm{mL}$. The cellulase activity $(\sim 1.2$ to $2.5 \mathrm{IU} / \mathrm{mL}$ ) per unit volume of enzyme broth and the yield of cellulases were attributed to the growth of the Trichoderma sp. on the hemicellulose fraction of the PKC during its first phase and then on a cellulose fraction of the PKC during its later phase for cellulase production, with the PKC substrate in solid-state fermentation (Chahal, 1985). A research conducted by Chahal (1985) on solidstate fermentation of wheat straw with $T$. reesei showed high cellulase activity (16 to $17 \mathrm{IU} / \mathrm{mL}$ ) per unit volume of enzyme broth and high yields of cellulases were attributed to the growth of $T$. reesei as well as to the close contact of hyphae with the substrate in solid-state fermentation.

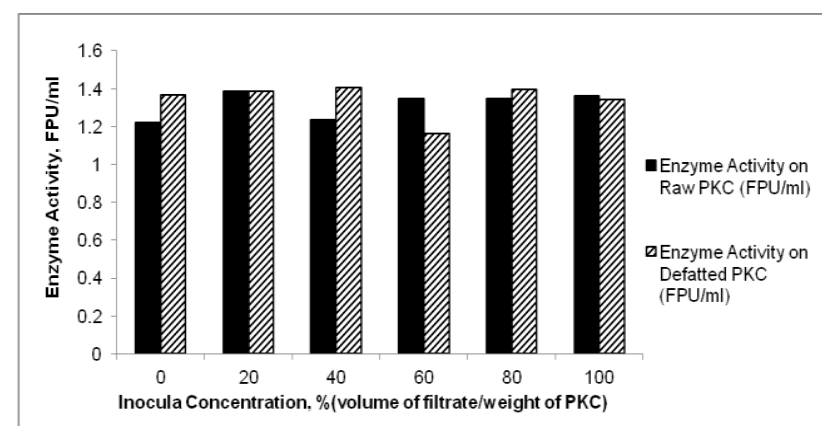

Figure 7: Cellulase activity of raw and defatted palm kernel cake solid state fermentation (PKC SSF) with different volumes of crude fungal filtrate

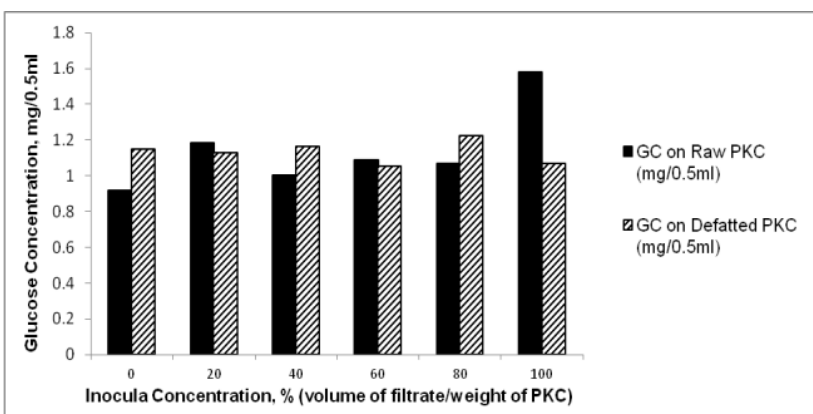

Figure 8: Glucose concentrations from raw and defatted palm kernel cake solid state fermentation (PKC SSF) with different volumes of crude fungal filtrate

Raw PKC originated from a palm oil factory. The oil residues in the PKC have been removed through expeller pressing; however about 6-8 \% of residual oil remain in the PKC. The expeller pressing alters the palm kernel physical structure, flattening the cells and this provides the fungi greater ease to breakdown the cellulosic components and potentially enhancing the celulase production (Roslan et al., 2009). The defatted PKC had undergone oil removal via hexane digestion. The residual hexane in the palm kernel cake could have adverse effect on the microorganism such as fungi or deactivates enzymes produced by the fungi. Until recently, it was assumed that enzymes added to organic solvents would lose activity and likely to be denatured and this issues of enzyme inactivation in organic solvents has been reported and studied by Fagain et al. (2003) who have reviewed the bioreactor stability, shelf life and operational stability of a variety of enzymes suspended in a neat organic solvent and aqueous-organic solvent mix. This will explains why the defatted PKC gave lower cellulase activity compared to raw PKC.

\section{Difference in Enzyme Activities between Mycelial Plug and Conidia as Inocula}

The conidia inocula produced higher cellulase activity in defatted PKC than raw PKC. The enhancement of cellulase activity between raw PKC and defatted PKC was less than $1 \%$ with conidia as inocula. This may be due to the chemical content within the defatted PKC sample. The usage of hexane in the solvent extraction process of removing the remaining oil in the PKC may change the bond, active sites or functional groups for the enzyme reaction. As reported by Mozhaev et al., (1989) and Khmelnitsky et al., (1991), the addition of increasing concentrations of organic solvents into aqueous solutions of proteins will always results in protein denaturation which show itself in a decrease of enzymatic activity and a sudden change of protein spectra. For example, enzymes lose their activity because the substrates can no longer bind to the active site and because amino acid residues involved in stabilizing substrates transition states are no longer positioned to be able to do so. Autoclaving happened to be a good alternative in improving the accessibility of the PKC for enzymes and to avoid too high sugar loss. In addition, autoclaving can act as sterilization thus minimized the risk of microbial contamination (Jose et al., 2010).

\section{Relationship between the production of glucose and cellulase activity by Trichoderma sp. on PKC}

The enzyme production by fungi is more favored compared to bacteria when both are used on the oil cakes under solid state fermentation. This is attributed to the morphology and physiology of these molds which enable them to penetrate and colonize solid substrates (Sivaramakrishnan et al., 2007). Trichoderma sp. exhibits higher cellulase activity to breakdown the PKC giving higher glucose. For example, with the usage of Trichoderma's $60 \%$ (wt/wt) SMP to the PKC, it can improve the cellulase activity by more than $100 \%$ and doubled the glucose concentrations if compare to the original PKC without inoculations.

Many fungi are able to produce extracellular enzymes that can act on polysaccharides. Cellulose is able to be 
decomposed to cellobiose via long1-4 anhydroglucose chains by the extracellular enzymes of many Ascomycetes, Fungi Imperfecti and Basidiomycetes, especially the Homobasidiomycetes. The fungal stages of cellulose decomposition occur within the cell where cellobiase breaks down cellobiose to utilizable glucose units. So, more glucose can be detected. Lignin is thought to be decomposed mainly by Basidiomycete fungi, and the breakdown may be by the release of aromatic units from the lignin molecule. Further breakdown is probably carried out by a wider range of fungi (Smith and Berry, 1975).

\section{CONCLUSION}

Overall, raw PKC fermented with $60 \%$ (wt/wt) solid mycelia plug to PKC gave the highest cellulase activity circa $2.454 \mathrm{FPU} / \mathrm{mL}$ an increase of more than $100 \%$ in cellulase activity. Fermentation of defatted PKC with $12 \mathrm{x}$ $10^{6}$ conidia/mL yields the maximum cellulase activity of $1.856 \mathrm{FPU} / \mathrm{mL}$ with an enhancement of $46.5 \%$ of cellulase activity. Crude fungal filtrate yield maximum increase in cellulase activity on raw and defatted PKC are $13.58 \%$ and $2.86 \%$ respectively using culture filtrate.

The current study clearly indicates that palm kernel cake can be used as one of the carbon sources for the production of cellulase activity by fungus Trichoderma sp. in the form of solid fungal mycelia plug, where more than $100 \%$ increased cellulase activity can be observed. Fungal conidia are also a better choice in enhancing cellulase activity of Trichoderma sp. permitted that the PKC used is devoid of oil.

\section{ACKNOWLEDGEMENT}

Authors wish to express their gratitude to the other colleagues for their support of the research. Authors also wants to acknowledge Pro-Fil Company, Fleet Palms Sdn. Bhd and Universiti Sains Malaysia (USM) for funding the research and School of Industrial Technology, USM, for the research resources, equipment and facilities provided. Special thanks to Mr. Arif Razali, Mrs. Shalima and Ms. Iliyana for the help during the experiment.

\section{REFERENCES}

AOAC, 1997. Official Methods of Analysis of AOAC International, $16^{\text {th }}$ Edn.(Cunniff, P.A. Eds). Virginia AOAC International, 25-28.

Cerveróa, J.M., Skovgaardb, P.A.,Felbyb, C.,Sørensenc, H.R. and Jørgensenb, H. (2010). Enzymatic hydrolysis and fermentation of palm kernel press cake for production of bioethanol. Enzyme and Microbial Technology 46 (2010): 177-184.

Chahal, D.S. (1985). Solid State Fermentation with Trichoderma reesei for Cellulase Production. Applied and Environmental Microbiology 49 (1): 205-210.

Choi, H.Y. and Gandipon, R. (2006). Production of fermented palm kernel cake (pkc). USPTO Patent Application 20060292264
Department of Statistics, Malaysia (2003). http://www.statistics.gov.my/portal/index. (Accessed on 5 July 2009)

Durand, A. and Chereau, D. (1988). A new pilot reactor for solid state fermentation: application to the protein enrichment of sugar beet pulp. Biotechnology and Bioengineering 31(5): 476-486.

Durand, A., Renaud, R., Maratray, J., Almanza, S., Diez, M. (1996). INRA-Dijon reactors for solid state fermentation : designs and applications. Journal of scientific and Industrial Research 55(5-6): 317-322.

Fagain, C.O. (2003). Enzyme stabilization-recent experimental progress. Enzyme and Microbial Technology 33:137-149.

Fernandez, M., Perez-Correa, J.R., Solar, I., Agosin E. (1996). Automation of solid substrate cultivation pilot reactor. Bioprocess Engineering 16(1): 1-4.

Ghose, T.K. (1987). Measurement of cellulase activities. Pure and Applied Chemistry 59 (2): 257-268.

Gupte, A. and Madamwar, D. (1997). Solid State fermentation of lignocellulosic waste for cellulase and $\beta$-glucosidase production by cocultivation of Aspergillus elipticus and Aspergillus fumigates. Biotechnology Progress 13(2): 166-169.

Gutierrez-Correa, M. and Tangerdy, R.R. (1998). Xylanase production by fungal mixed culture solid substrate fermentation on sugar cane bagase. Biotechnology Letters 20(1): 45-47.

Hang, Y.D. and Woodams, E.E. (1998). Production of citric acid from corncobs by Aspergillus niger. Bioresource Technology 65(3): 251-253.

Hong, L.S., Darah, I. and Ibrahim, C.O. (2011). Lignocellulolytic materials as a raw material for the production of fermentable sugars via solid state fermentation. Asian Journal of Scientific Research 4(1): 53-61

lluyemi, F.B., Hanafi, M.M., Radziah, O. and Kamarudin, M.S. (2006). Fungal solid state culture of palm kernel cake. Bioresource Technology 97(3): 477482.

Khmelnitsky, Y.L., Mozhaev, V.V., Belova, A.B., Sergeeva, M.V. and Martinek, K. (1991). Denaturation capacity, a new quantitative criterion for selection of organic solvents as reaction media in Biocatalyst. European Journal of Biochemistry; 198(1): 31-41.

King, K.W.and Vessal, M.I. (1969). Enzymes of the cellulase complex, In: Cellulase and their Applications. Gould, R. F. (Eds.). American Chemical Society, Washington. pp.7-25.

Kotwal, S.M.,Gote, M.M., Sainkar, S.R., Khan M.I. and Khire J.M. (1998). Production of $\alpha$-galactosidase by thermophilic fungus Humicola $\mathrm{sp}$. in solid state fermentation and its application in soyamilk hydrolysis. Process Biochemistry 33(3): 337-343.

Kubicek, C.P. (1992). The cellulose proteins of Trichoderma Reesei: structure, multiplicity, mode of action and regulation of formation. Advances in Biochemical Engineering Biotechnology 45: 1-27. 
Lee, C.K., Darah, I. and Ibrahim, C.O. (2011). Production and Optimization of Cellulase enzyme using Aspergillus niger USM Al 1 and comparison with Trichoderma reesei via Solid State Fermentation system. Biotechnology Research International 2011: 658493

Mackul'ak, T., Prousek, J., Olejníková, P., Bodík, I. (2010). The using of enzymes for degradation of cellulose substrate for the production of biogas, Editor: Markoš, J., In Proceedings of the 37th International Conference of Slovak Society of Chemical Engineering, Tatranské Matliare, Slovakia. pp. 14071412.

Mandels, M., Andreotti, R. and Roche, C. (1976). Measurement of saccharifying cellulase, In: Enzymatic Conversion of Cellulosic Materials Technology and Applications. John Wiley \& Sons, New York. p. 21.

Mozhaev, V.V., Khmelnitsky, Y.L., Sergeeva, M.V., Belova, A.B., Klyachko, N.L., Levashov, A.V. and Martinek, K.(1989). Catalytic activity and denaturation of enzymes in water/organic cosolvent mixtures. Alpha-chymotrypsin and laccase in mixed water/alcohol, water/glycol and water/formamide solvents. European Journal of Biochemistry 184 (3): 597-602.

Panagiotou, G., Kekos,D., Macris, B.J. and Christakopoulos, P. (2003). Production of cellulolytic and xylanolytic enzymes by Fusarium oxysporum grown on corn stover in solid state fermentation. Industrial Crops and Products 18: 37-45.

Pang, P.K., Darah, I., Poppe, L., Szakacs, G. and Ibrahim, C.O. (2006a). Xylanase production by a local isolate, Trichoderma spp. FETL c3-2 via solid state fermentation using agricultural wastes as substrates. Malaysian Journal of Microbiology 2(1): 7-14.

Pang, P.K., Darah, I., Poppe, L., Szakacs, G. and Ibrahim, C.O. (2006b). Production of cellullolytic enzymes by a newly isolated, Trichoderma sp. FETL c3-2 via solid state fermentation grown on sugar cane bagasse : Palm Kernel Cake as substrates. Pakistan Journal of Biological Sciences 9(8): 1430-1437.

Pricart, P., Diaz, P. and Pastor, F.I.J. (2007). Lett. App. Microbiol., 34, 108133.

Raghavarao, K.S.M.S., Ranganathan, T.V. and Karanth, N.G. (2003). Some engineering aspects of solid-state fermentation. Biochemical Engineering 13: 127-135.

Roslan, A.M., Hassan, M.A., Abd-Aziz, S. and Yee, P.L. (2009). Effect of Palm Oil Mill Effluent Supplementation on Cellulase Production from Rice Straw by Local Fungal Isolates. International Journal of Agricultural Research 4 (5): 185-192.

Saenphoom, P., Liang, J.B., Ho, Y.W., Loh, T.C. and Rosfarizan, M. (2011). Effect of enzyme treatment on chemical composition and production of reducing sugars in palm (Elaeis guineenis) kernel expeller. African Journal of Biotechnology 10(68): 1537215377.

Sekar, C. and Balaraman, K. (1998). Optimization studies on the production of cyclosporine A by solid state fermentation. Bioprocess Engineering 18(4): 293-296.

Sivaramakrishnan, S., Gangadharan, D. and Nampoothiri, K.M. (2007). Alpha amylase production by Aspergillus oryzae employing solid state fermentation., Journal of Scientific and Industrial Research India 66: 621-626.

Smith, J.E. and Berry, D.R. (1975). The Filamentous Fungi, Edward Arnold, Volume 1: Industrial Mycology.

Teeri, T.T., Penttila, M., Keranen, S., Nevalainen, H. and Knowles, J.K.C. (1992). Structure, function and genetics of cellulases, In: Biotechnology of filamentous fungi : technology and products. Finkelstein, D.B. and Ball, C. (Eds.). Butterworth-Heinemann, Boston. pp 417-445.

Weiland, P. (1988). Principles of Solid State Fermentation, In : Treatment of lignocellulosics with white rot fungi. Zadrazil, F. and Reniger, P. (Eds.). Elsevier, London. pp 64-67.

Xue, M., Liu, D., Zhang, H., Qi, H. and Lei, Z. (1992). A pilot process of solid state fermentation from sugar beet pulp for the production of microbial protein. Journal of Fermentation and Bioengineering 73(3): 203-205.

Y.B. Datuk Peter Chin Fah Kui. (2005). Minister of plantation industries and commodities. In Conjunction (Malaysia) with his speech at the $45^{\text {th }}$ Anniversary Dinner of The Malayan Edible Oil Manufacturers' Association (MEOMA), Renaissance Kuala Lumpur Hotel, Malaysia, on 23 July 2005. 